Journal of Advanced Research in Fluid Mechanics and Thermal Sciences

\title{
Boundary Layer Flow of Dusty Williamson Fluid with Variable Viscosity Effect Over a Stretching Sheet
}

\author{
Nur Syamilah Arifin ${ }^{1,}$, Abdul Rahman Mohd Kasim ${ }^{2, *}$, Syazwani Mohd Zokri ${ }^{3}$, Mohd Zuki Salleh² \\ 1 Fakulti Sains Komputer \& Matematik, Universiti Teknologi MARA, Cawangan Johor, Kampus Pasir Gudang, 81750 Masai, Johor, Malaysia \\ Pusat Sains Matematik, Universiti Malaysia Pahang, Lebuhraya Tun Razak, 26300 Gambang, Kuantan, Pahang, Malaysia \\ 3 Fakulti Sains Komputer \& Matematik, Universiti Teknologi MARA, Cawangan Terengganu, Kampus Kuala Terengganu, 21080 Terengganu, \\ Malaysia
}

\section{Article history:}

Received 25 April 2021

Received in revised form 2 July 2021

Accepted 7 July 2021

Available online 19 August 2021
Keywords:

Two-phase flow; variable viscosity; Dusty Williamson fluid; boundary layer

\section{ABSTRACT}

Numerical investigation of the boundary layer flow of Williamson fluid with the presence of dust particles over a stretching sheet is carried out by taking into account the variable viscosity effect and Newtonian heating boundary condition. The genuinely two-phase flow model which has been proved to be compatible to present the mutual relationship between non-Newtonian fluid and solid particles is considered in this present study. To be precise, the governing equations are initially transformed into ordinary differential equations through formulation process before proceeding further with the numerical computation by using Keller-box method. The resulting equations are then programmed in MATLAB software. The obtained numerical results are validated with existing study found in open literature and a good agreement is achieved. The influence of pertinent parameters on velocity and temperature profiles, skin friction coefficient together with Nusselt number is presented in graphical and tabular forms. Results revealed that the increasing Williamson parameter decreases the fluid velocity of both fluid and dust phases. It is expected that the present numerical results could conceivably help in predicting the boundary layer problem arising in two-phase flow in the future.

\section{Introduction}

Research activities on boundary layer flow associated with two-phase problem have been extensively published due to its many engineering applications such as purification of crude oil, blood flow, sedimentation, and etc. This problem involves mutual relationship between two-phase or components in a flow system and able to interact simultaneously with each other. Note that, the main focus of this present study is to delve into the flow of fluid (fluid phase) embedded with solid (solid phase) in the form of dust particles. One of the important aspects of this problem for fluid

\footnotetext{
* Corresponding author.

E-mail address: nursyamilaharifin@uitm.edu.my

* Corresponding author.

E-mail address: rahmanmohd@ump.edu.my
}

https://doi.org/10.37934/arfmts.86.1.164175 
phase is that it can treated as Newtonian and non-Newtonian fluids which stimulates continuing interest within this area of research. Theoretical works covering on suspension of dust particles in Newtonian fluid with dissimilar circumstances have been reported by several researchers, as documented in [1-5]. A recent study reported by Kumar et al., [6] caters the problem on dusty fluid flow under the effect of mixed convection over a stretching cylinder by taking into account the nanoparticles. Meanwhile, Gajjela and Nandkeolyar [7] concentrated on the viscous dissipation effect on dusty fluid and Koriko et al., [8] unravel the behaviour of fluid flow displayed by dusty Carreau nanofluid. A few more interesting results on non-Newtonian based fluid incorporated with dust particles for diverse situations have been acquired by many authors [9-13]. With regard to Jeffrey fluid, Kasim et al., [14] presented the solution of the aligned magnetic flow containing spherical particles over a vertical stretching sheet and in subsequent years, they took the initiative to measure the thermal radiation effect with similar condition [15]. On the other hand, recently, Dinesh et al., [16] and Bilal et al., [17] obtained the exact solution for magnetohydrodynamic (MHD) flow problem of dusty viscoelastic fluid in irregular channel and rotating frame, respectively. Apart from that, research activities on non-Newtonian fluid with miscellaneous circumstances have been widely investigated [18-28].

All the studies reviewed so far focused on the fixed physical properties which suggested that the viscosity of fluid is constant or changes with shear stress. Nevertheless, there are certain elements that are noteworthy to be considered which may influence the particular property such as temperature and in view of this, further investigation is required [29]. In the case of single phase flow of Newtonian fluid, Tshehla [30] examined the temperature dependent variable viscosity on boundary layer flow across inclined plane. They also point out the pronounced changes in the fluid flow structure on account of varying the viscosity with temperature. Under the category of nonNewtonian fluid, a number of studies concerning stretching sheet flow for Williamson fluid have comprehensively described in [31-33] and for Eyring Powell fluid, can be found in [34-35]. Some more problems on the impact of viscosity dependency have also been published, however, the main focus is on two-phase flow [36-38].

In view of all that have been mentioned so far, the growing literature in investigating viscosity dependency for various conditions can be noticed which proved that this effect is gaining prominence and there has been litter discussion involving two-phase flow. Besides, the present study aims to evaluate the two-phase flow of dusty Williamson fluid over a vertical stretching sheet by highlighting the effect of variable viscosity. Numerical method of Keller-box is applied as a tool for obtaining the solutions with the help of MATLAB software.

\section{Problem Formulation}

This study is devoted to examine the behaviour of two-phase flow problem on dusty Williamson fluid under the influence of variable viscosity over a vertical stretching sheet by considering Newtonian heating $(\mathrm{NH})$ as a thermal boundary condition. Note that, the analysis is conducted by means of a steady, two-dimensional and incompressible Williamson fluid defined here. Additionally, dust particles are assumed to be uniform in size, spherical shape and non-interacting. The physical configuration of the sheet can be clearly seen in Figure 1, where $x$-axis is positioned vertically upward along the sheet with $y$-axis being perpendicular to it. 


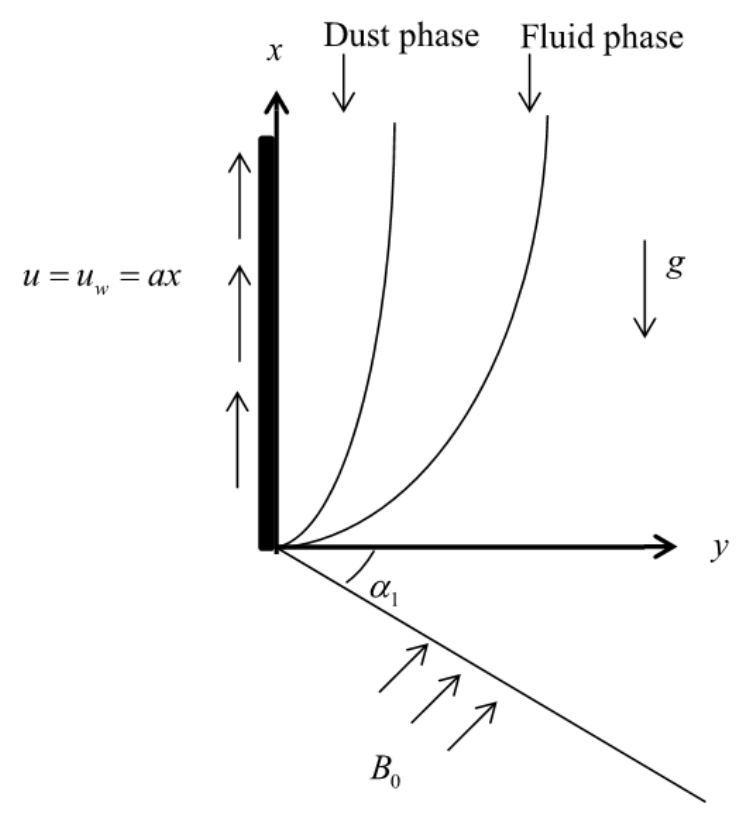

Fig. 1. Flow configuration of dusty Williamson fluid

To solve the problem, the following governing boundary layer equations of Williamson fluid and dust particles are taken into account.

Fluid phase:

$\frac{\partial u}{\partial x}+\frac{\partial v}{\partial y}=0$

$u \frac{\partial u}{\partial x}+v \frac{\partial u}{\partial y}=\frac{1}{\rho} \frac{\partial}{\partial y}\left(\mu(T) \frac{\partial u}{\partial y}\right)+\frac{\sqrt{2} \Gamma}{\rho}\left[\frac{\partial}{\partial y}\left(\mu(T) \frac{\partial u}{\partial y}\right) \frac{\partial u}{\partial y}\right]+\frac{\rho_{p}}{\rho \tau_{v}}\left(u_{p}-u\right)$

$\rho c_{p}\left(u \frac{\partial T}{\partial x}+v \frac{\partial T}{\partial y}\right)=k\left(\frac{\partial^{2} T}{\partial y^{2}}\right)+\frac{\rho_{p} c_{s}}{\gamma_{T}}\left(T_{p}-T\right)$,

Dust phase:

$\frac{\partial}{\partial x}\left(u_{p}\right)+\frac{\partial}{\partial y}\left(v_{p}\right)=0$

$\rho_{p}\left(u_{p} \frac{\partial u_{p}}{\partial x}+v_{p} \frac{\partial u_{p}}{\partial y}\right)=\frac{\rho_{p}}{\tau_{v}}\left(u-u_{p}\right)$

$\rho_{p} c_{s}\left(u_{p} \frac{\partial T_{p}}{\partial x}+v_{p} \frac{\partial T_{p}}{\partial y}\right)=-\frac{\rho_{p} c_{s}}{\gamma_{T}}\left(T_{p}-T\right)$

The boundary conditions of $\mathrm{NH}$ are in the form 


$$
\begin{aligned}
& u=u_{w}(x)=a x, v=0, \frac{\partial T}{\partial y}=-h_{s} T \text { at } y=0 \\
& u \rightarrow 0, u_{p} \rightarrow 0, v_{p} \rightarrow v, T \rightarrow T_{\infty}, T_{p} \rightarrow T_{\infty} \text { at } y \rightarrow \infty
\end{aligned}
$$

where $(u, v)$ and $\left(u_{p}, v_{p}\right)$ are the velocities components of the fluid and particle phases along $x$ and $y$ axes, respectively. $\mu(T)$ is the variable viscosity, $\rho$ and $\rho_{p}$ are the density of fluid and dust phase, $\tau_{v}=1 / k$ is the relaxation time of particles phase, $k$ is the Stoke's resistance (drag force), $c_{p}$ and $c_{s}$ are specific heat of fluid and dust particle, $T$ and $T_{p}$ are the temperature of fluid and particle phases, $\gamma_{T}$ is the thermal relaxation time, $a$ is positive constant and $h_{s}$ is heat transfer parameter. It is important to note that, the viscosity, $\mu$ considered herein follows the robust Reynold exponential model which can be defined as [39]

$$
\mu(T)=e^{-\alpha \theta(\eta)}=1-\alpha \theta(\eta)
$$

where $\alpha$ is the viscosity parameter. Eq. (1)-(7) are required to be transformed into a convenient form to facilitate the numerical computation of this study. Therefore, the similarity transformation as expressed in Eq. (9) is implemented, given by

$$
\begin{aligned}
& u=a x f^{\prime}(\eta), \quad v=-(a v)^{1 / 2} f(\eta), \quad \eta=\left(\frac{a}{v}\right)^{1 / 2} y, \quad \theta(\eta)=\frac{T-T_{\infty}}{T_{\infty}} \\
& u_{p}=a x F^{\prime}(\eta), \quad v_{p}=-(a v)^{1 / 2} F(\eta), \quad \theta_{p}(\eta)=\frac{T_{p}-T_{\infty}}{T_{\infty}}
\end{aligned}
$$

where $\psi$ is the stream function defined as $u=\partial \psi / \partial y$ and $v=-\partial \psi / \partial x$. The equations can now be expressed as follows

$$
\begin{gathered}
\begin{array}{c}
(1-\alpha \theta(\eta)) f^{\prime \prime \prime}(\eta)\left[1+f^{\prime \prime}(\eta)\right]-\alpha \theta^{\prime}(\eta)\left[\lambda_{3}\left(f^{\prime \prime}(\eta)\right)^{2}+f^{\prime \prime}(\eta)\right]-\left(f^{\prime}(\eta)\right)^{2}+f(\eta) f^{\prime \prime}(\eta) \\
+
\end{array} \\
\begin{array}{c}
\left.\theta^{\prime \prime}(\eta)+\operatorname{Pr} f(\eta) F^{\prime}(\eta)-f^{\prime}(\eta)\right)=0 \\
(\eta)+\frac{2}{3} \beta N\left(\theta_{p}(\eta)-\theta(\eta)\right)=0
\end{array} \\
\left(F^{\prime}(\eta)\right)^{2}-F(\eta) F^{\prime \prime}(\eta)+\beta\left(F^{\prime}(\eta)-f^{\prime}(\eta)\right)=0 \\
\theta_{p}^{\prime}(\eta) F(\eta)+\frac{2}{3} \frac{\beta}{\operatorname{Pr} \gamma}\left(\theta(\eta)-\theta_{p}(\eta)\right)=0
\end{gathered}
$$

and the boundary conditions (7) are reduced to

$$
f(0)=0, f^{\prime}(0)=1, \quad \theta^{\prime}(0)=-b(1+\theta(0)) \text { at } \eta=0
$$




$$
f^{\prime}(\eta) \rightarrow 0, F(\eta) \rightarrow 0, F(\eta) \rightarrow f(\eta), \theta(\eta) \rightarrow 0, \theta_{p}(\eta) \rightarrow 0 \text { at } \eta \rightarrow \infty
$$

where a prime ( $\left.{ }^{\prime}\right)$ denotes differentiation with respect to $\eta \cdot N=\rho_{p} / \rho$ is the mass concentration of particle phase, $\beta=1 / a \tau_{v}$ is the fluid-particle interaction parameter, $\operatorname{Pr}=\mu c_{p} / k$ is the Prandtl number, $\gamma=c_{s} / c_{p}$ is the specific heat ratio of mixture, $b=-h_{s}(v / a)^{1 / 2}$ is the conjugate parameter for $\mathrm{NH}$ and $\lambda_{3}=\sqrt{2 a^{3} / v} \Gamma x$ is the Williamson parameter. As referred to Crane [40], the exact solution for Eq. (10) by ignoring the effects of viscosity dependency and dust particles can be expressed as

$$
\theta(\eta)=C_{1} \int_{\eta}^{\infty} e^{-\operatorname{Pr} \int_{\eta}^{\infty} f d \eta} d \eta, C_{1}=\frac{-b(1+\theta(0))}{e^{-\operatorname{Pr} \int_{\eta}^{\infty} f d \eta}}
$$

Furthermore, the physical quantities of skin friction coefficient and Nusselt number are given as

$$
C_{f} \operatorname{Re}_{x}^{1 / 2}=[1-\alpha \theta(\eta)]\left(f^{\prime \prime}(0)+\frac{\lambda_{3}}{2}\left(f^{\prime \prime}(0)\right)^{2}\right), N u_{x} \operatorname{Re}_{x}^{-1 / 2}=b\left(\frac{1}{\theta(0)}+1\right)
$$

\section{Numerical Procedure}

The Keller box method is employed for the purpose of obtaining numerical results of the present problem. In view of this, Eq. (10)-(14) are translated into programming languages and further computed in MATLAB software. A direct comparison between the results generated here and previous published work is therefore needed in order to prove the authentic of applied numerical method. Once accomplished, the computational process continues by selecting the boundary layer thickness, $\eta_{\infty}=8$ and step size, $\Delta \eta=0.02$ to which the results are revealed in the forthcoming figures and tables.

\section{Results and Discussion}

The response of pertinent parameters on velocity and temperature profiles, skin friction coefficient as well as Nusselt number is primary concerned in this section. For this, the variations in considered parameters are evaluated by fixing $\operatorname{Pr}=7, \alpha=b=0.1, \gamma=0.3, \lambda=B=N=0.5$ unless for the measured one. The computation is initially started by transforming the present model into the existing model which arising Newtonian fluid flow problem for the verification purpose. Table 1 shows the comparative data between exact solution and numerical solution reported by Salleh et al., [41] as well as current study. From the table, the obtained results are observed to experience exactness up to 3 decimal digits with exact solution. Thus, the numerical algorithm developed here is considered to be accurate and computation process for the involved parameters can be carried out accordingly. Next, Table 2 presents the skin friction coefficient, $C_{f} \operatorname{Re}_{x}{ }^{1 / 2}$ and Nusselt number, $N u_{x} \operatorname{Re}_{x}^{-1 / 2}$ for assorted values of $\alpha, \beta$ and $\lambda_{3}$. Both physical quantities share similar trend correspond to increasing values of $\beta$ and $\lambda_{3}$, respectively, for which intensifying performance is observed for the first parameter while reducing in latter parameter. The opposite trend in two quantities is noticed as $\alpha$ increases.

The distribution of velocity and temperature profiles for both fluid and dust phases are portrayed in Figure 2 to 7, where insignificant changes can be discovered in almost figures. Figures 2 and 3 show 
the influence of $\alpha$ on velocity and temperature profiles. It can be seen that, the velocity profile of dust phase decreases near to surface and then conversely found to increase as $\alpha$ escalates. Meanwhile, the fluid remains increased across the surface when $\alpha$ is enhanced. For the temperature profile, it is noticed to decrease in all phases as $\alpha$ grows.

Figure 4 and 5 present the behaviour of Williamson fluid and dust particles in response to the variations in $\lambda_{3}$. In both figures, no marked reduction is found in velocity profile, whilst temperature profile elevates with any increase in values of $\lambda_{3}$. This result may be explained by the fact that, the viscosity of the fluid is physically ascended which then leads to additional resistance to the fluid flow and ultimately decelerates the velocity distribution.

On the other hand, Figure 6 and 7 display the effect of dust particles in Williamson fluid by measuring the parameters $\beta$. As a result of enlarging values of $\beta$, the velocity of dust particles is noticed to escalate, with a corresponding decrease in Williamson velocity. This result can be reasoned that an enhancement in $\beta$ deteriorates the velocity relaxation time of dust particles in which the particles alter itself to reach the fluid velocity. Thus, there exists the propensity for particles to accelerate and consequently decelerates the fluid motion. In the case of temperature profile, the two phases experience a decreasing trend as the effect of $\beta$ becomes larger.

\section{Table 1}

Comparative values of surface temperature $\theta(0)$ for various values of $\operatorname{Pr}$ when $\beta=N=\lambda_{3}=\alpha=0, \gamma \rightarrow \infty$ and $b=1$

\begin{tabular}{llll}
\hline & & & \\
\hline $\operatorname{Pr}$ & Exact Eq. (15) & Salleh et al., [41] & Present \\
\hline 3 & 6.05159 & 6.02577 & 6.05176 \\
5 & 1.760395 & 1.76594 & 1.76583 \\
7 & 1.116815 & 1.13511 & 1.11996 \\
10 & 0.764524 & 0.76531 & 0.76531 \\
\hline
\end{tabular}

\section{Table 2}

Variation of $-C_{f} \operatorname{Re}_{x}^{1 / 2}$ and $N u_{x} \operatorname{Re}_{x}^{-1 / 2}$ for various values of $\alpha, \lambda_{3}$ and $\beta$

\begin{tabular}{lllll}
\hline$\alpha$ & $\lambda_{3}$ & $\beta$ & $-C_{f} \mathrm{Re}_{x}{ }^{1 / 2}$ & $N u_{x} \operatorname{Re}_{x}{ }^{-1 / 2}$ \\
\hline 0.01 & 0.5 & 0.5 & 0.93825 & 2.26737 \\
0.05 & & & 0.93561 & 2.26851 \\
0.1 & & & 0.93234 & 2.26872 \\
0.2 & & & 0.92586 & 2.27093 \\
0.1 & 0.3 & 0.5 & 0.99703 & 2.30030 \\
& 0.4 & & 0.96795 & 2.28734 \\
& 0.5 & & 0.93234 & 2.26872 \\
& 0.6 & & 0.82409 & 2.19961 \\
0.1 & 0.5 & 0.5 & 0.93234 & 2.26872 \\
& & 1.5 & 0.96953 & 2.30332 \\
& & 2.5 & 0.98271 & 2.33303 \\
& & 3.5 & 0.98869 & 2.35366 \\
\hline
\end{tabular}




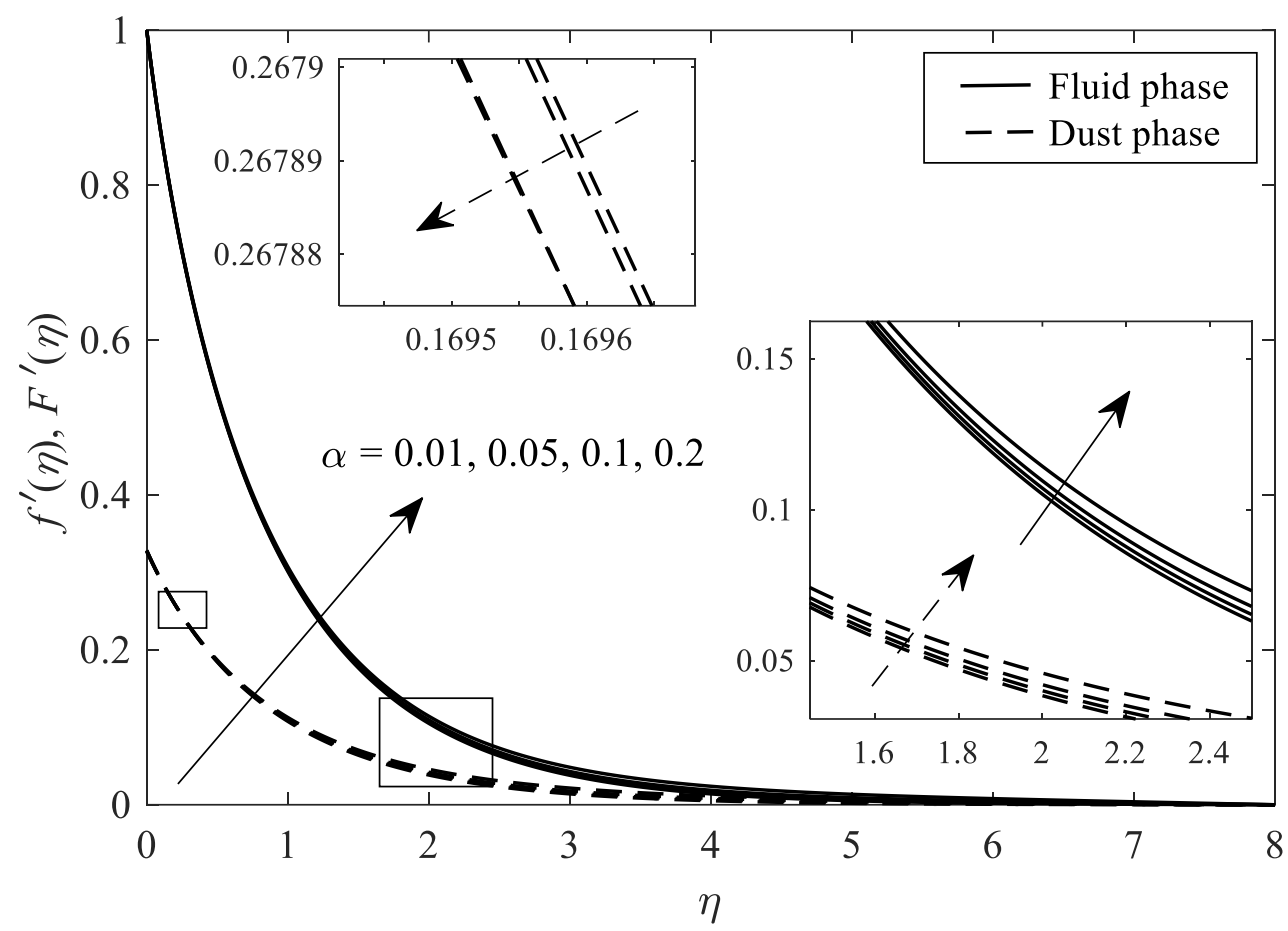

Fig. 2. Velocity profile for various values of $\alpha$

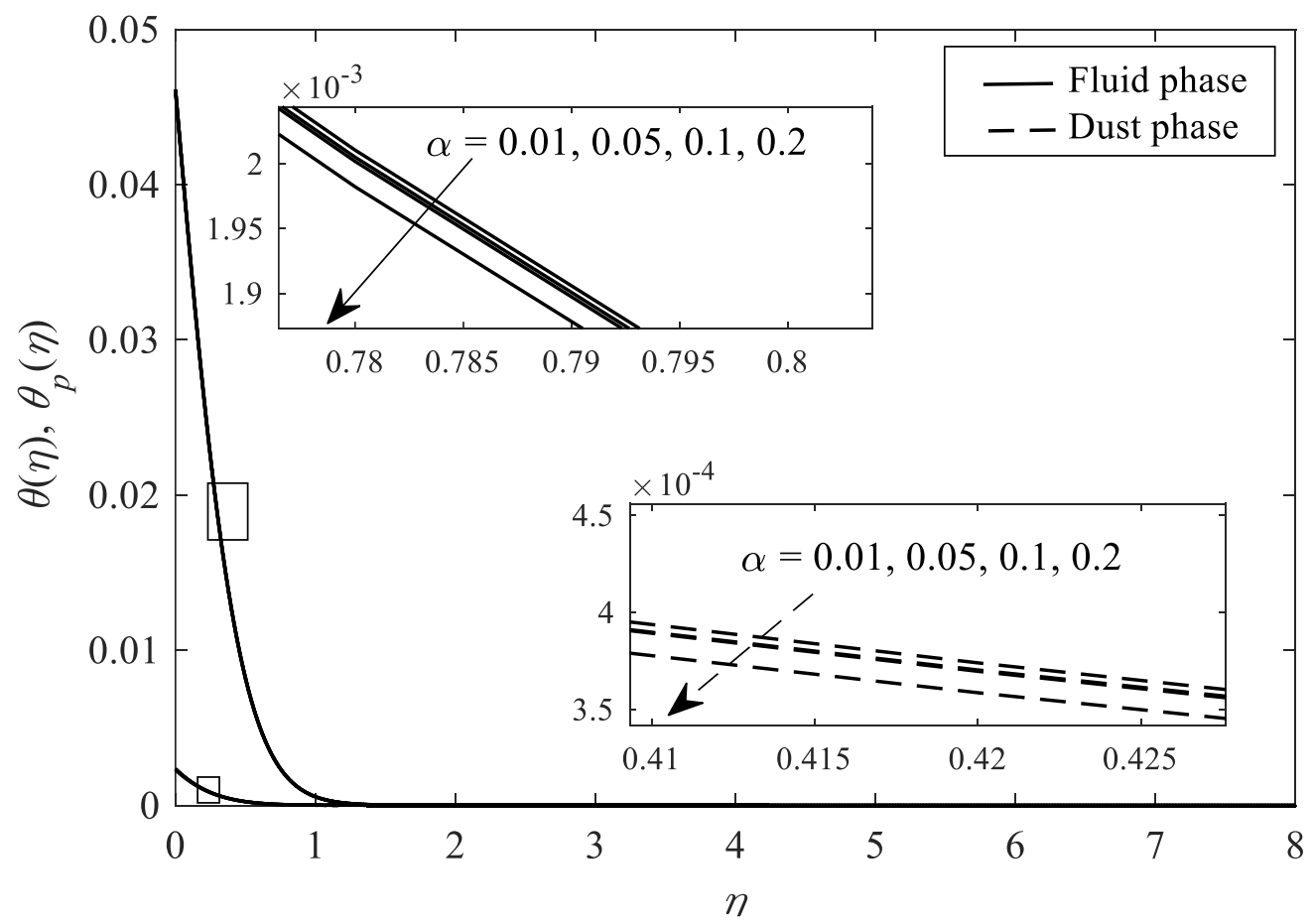

Fig. 3. Temperature profile for various values of $\alpha$ 


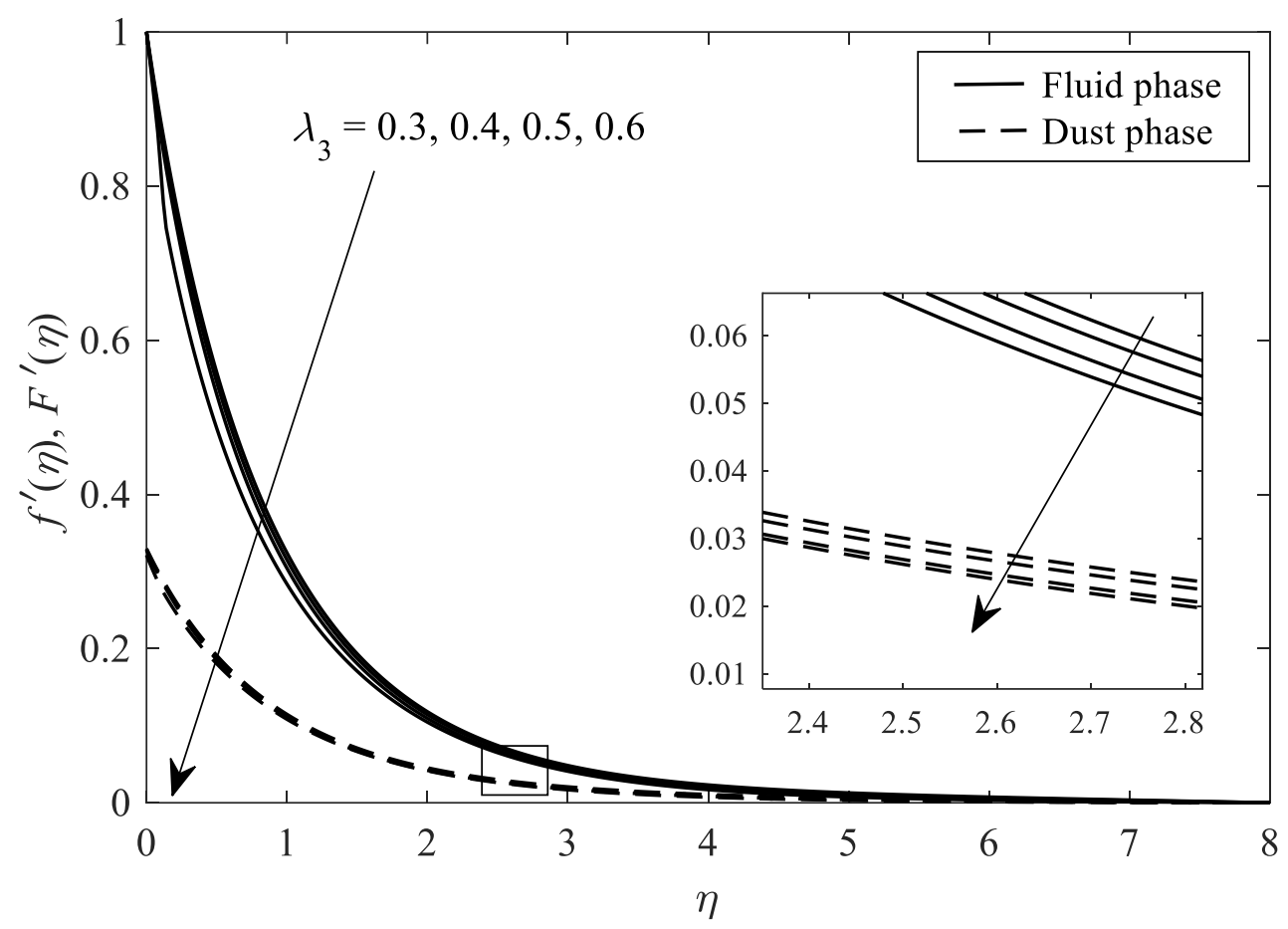

Fig. 4. Velocity profile for various values of $\lambda_{3}$

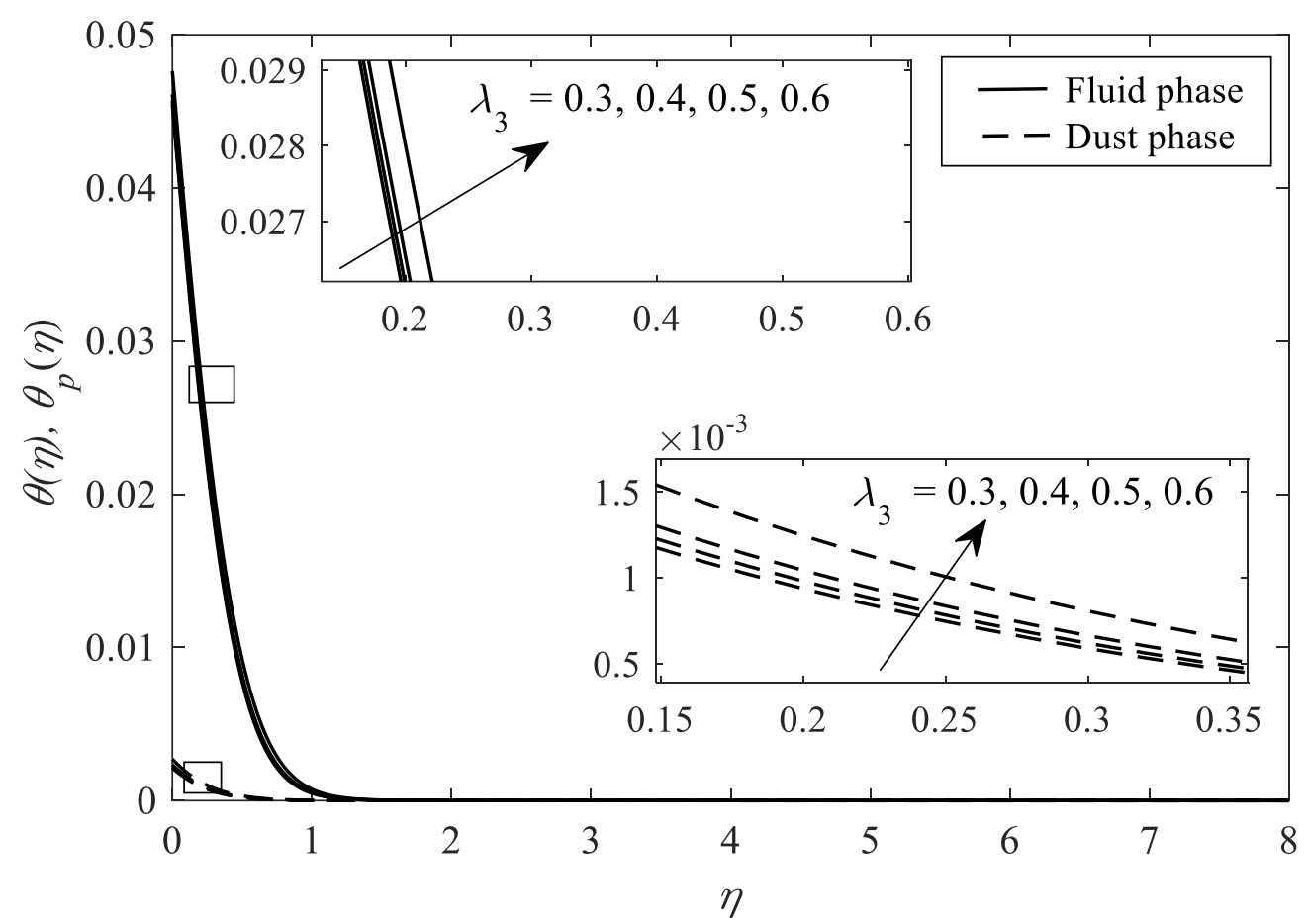

Fig. 5. Temperature profile for various values of $\lambda_{3}$ 


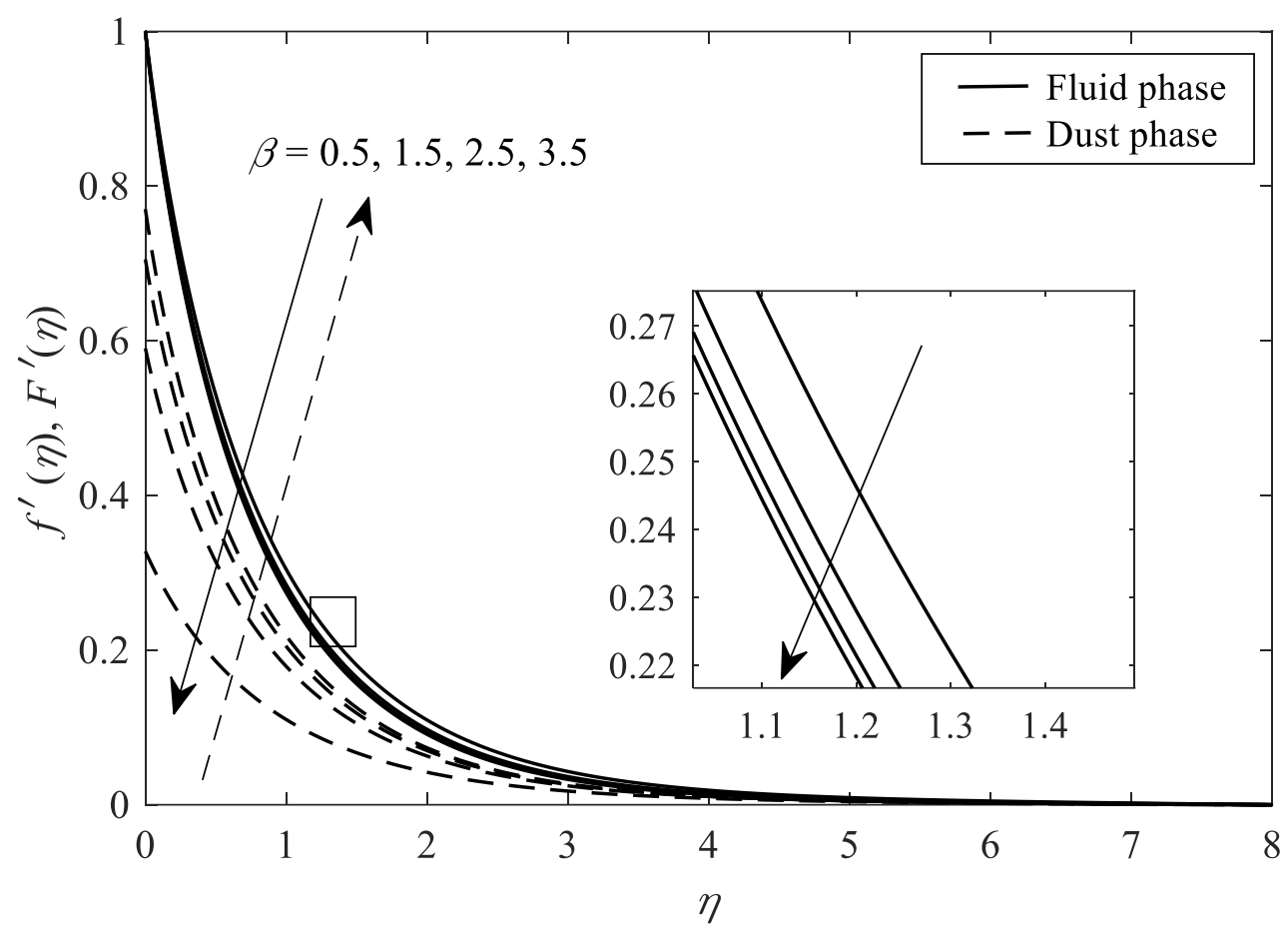

Fig. 6. Velocity profile for various values of $\beta$

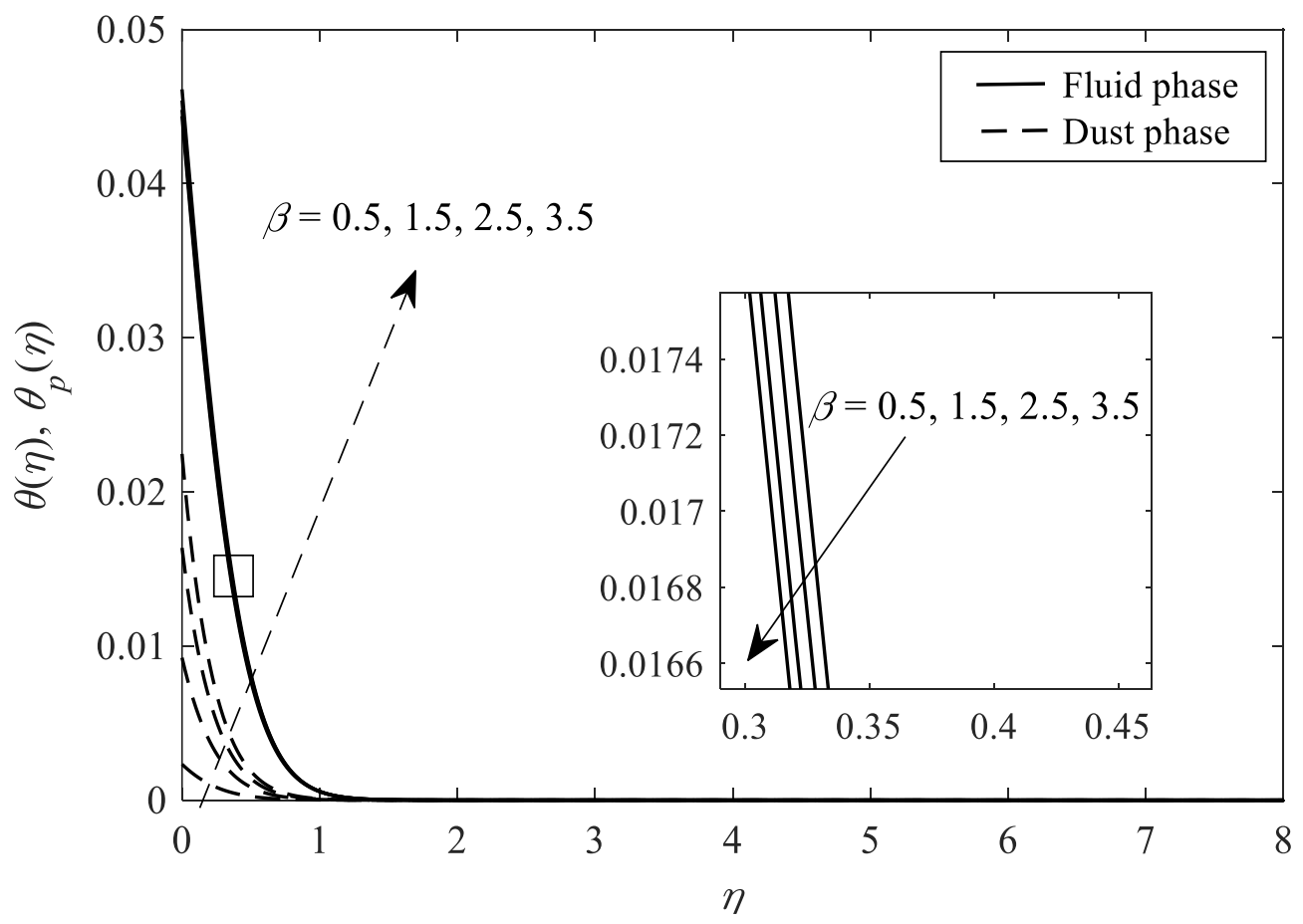

Fig. 7. Temperature profile for various values of $\beta$

\section{Conclusion}

The study undertaken here is to determine the influence of variable viscosity on the two-phase flow of both Williamson fluid and dust particles. Additionally, the surface of the sheet is exposed with boundary conditions of Newtonian heating $(\mathrm{NH})$ and the Keller-box method is applied to aid the numerical computational process. Summing up from the obtained results that recorded on the aforementioned figures and tables, the findings to emerge from this study are 
i. the velocity profile of both phases shares the similar trend on which they increase as $\alpha$ and $\lambda_{3}$ increases, whereas reverse trend occurs for $\beta$,

ii. the temperature profile of both phases increases with the increase of $\lambda_{3}$ and $\beta$, whereas reverse trend occurs for $\lambda_{3}$,

iii. the skin friction of fluid phase decreases with the increase of $\alpha$ and $\lambda_{3}$, while opposite trend happens for $\beta$,

iv. the Nusselt number of fluid phase increases as $\alpha$ and $\beta$ increases, while opposite trend happens for $\lambda_{3}$.

\section{Acknowledgement}

The authors wish to recognize the financial support of this project received from Universiti Malaysia Pahang through RDU182307 and RACER/1/2019/STG06/UMP//1. A grateful acknowledge also goes to Universiti Teknologi MARA Cawangan Johor for the guidance and encouragement.

\section{References}

[1] Isa, Sharena Mohamad, Anati Ali, and Sharidan Shafie. "Stagnation point flow of MHD dusty fluid toward stretching sheet with convective surface." Jurnal Teknologi 78, no. 3-2 (2016). https://doi.org/10.11113/it.v78.7820

[2] Butt, Adnan Saeed, Asif Ali, and Ahmer Mehmood. "Hydromagnetic stagnation point flow and heat transfer of particle suspended fluid towards a radially stretching sheet with heat generation." Proceedings of the National Academy of Sciences, India Section A: Physical Sciences 87, no. 3 (2017): 385-394. https://doi.org/10.1007/s40010$\underline{017-0370-9}$

[3] Arifin, N. S., S. M. Zokri, A. R. M. Kasim, M. Z. Salleh, and N. F. Mohammad. "The aligned magnetic field of a dusty fluid flow over a stretching sheet." In AIP Conference Proceedings, vol. 1870, no. 1, p. 040033. AIP Publishing LLC, 2017. https://doi.org/10.1063/1.4995865

[4] Siddiqa, Sadia, Naheed Begum, Md Anwar Hossain, Naeem Mustafa, and Rama Subba Reddy Gorla. "Two-phase dusty fluid flow along a cone with variable properties." Heat and Mass Transfer 53, no. 5 (2017): 1517-1525. https://doi.org/10.1007/s00231-016-1918-y

[5] Abbas, Z., J. Hasnain, and M. Sajid. "Effects of slip on MHD flow of a dusty fluid over a stretching sheet through porous space." Journal of Engineering Thermophysics 28, no. 1 (2019): 84-102. https://doi.org/10.1134/S1810232819010077

[6] Kumar, RS Varun, RJ Punith Gowda, R. Naveen Kumar, M. Radhika, and B. C. Prasannakumara. "Two-phase flow of dusty fluid with suspended hybrid nanoparticles over a stretching cylinder with modified Fourier heat flux." $S N$ Applied Sciences 3, no. 3 (2021): 1-9. https://doi.org/10.1007/s42452-021-04364-3

[7] Gajjela, Nagaraju, and Raj Nandkeolyar. "Investigating the magnetohydrodynamic flow of a couple stress dusty fluid along a stretching sheet in the presence of viscous dissipation and suction." Heat Transfer 50, no. 3 (2021): 27092724. https://doi.org/10.1002/htj.22001

[8] Koriko, Olubode Kolade, Kolawole S. Adegbie, Nehad Ali Shah, Isaac L. Animasaun, and M. Adejoke Olotu. "Numerical solutions of the partial differential equations for investigating the significance of partial slip due to lateral velocity and viscous dissipation: The case of blood-gold Carreau nanofluid and dusty fluid." Numerical Methods for Partial Differential Equations (2021). https://doi.org/10.1002/num.22754

[9] Arifin, Nur Syamilah, Syazwani Mohd Zokri, Abdul Rahman Mohd Kasim, Mohd Zuki Salleh, and Nurul Farahain Mohammad. "Two-phase mixed convection flow of dusty Williamson fluid with aligned magnetic field over a vertical stretching sheet." In Proceedings of the Third International Conference on Computing, Mathematics and Statistics (iCMS2017), pp. 209-216. Springer, Singapore, 2019. https://doi.org/10.1007/978-981-13-7279-7 26

[10] Arifin, N. S., S. M. Zokri, A. R. M. Kasim, M. Z. Salleh, N. F. Mohammad, and W. N. S. W. Yusoff. "Aligned magnetic field of two-phase mixed convection flow in dusty Casson fluid over a stretching sheet with Newtonian heating." In Journal of Physics: Conference Series, vol. 890, no. 1, p. 012001. IOP Publishing, 2017. https://doi.org/10.1088/1742-6596/890/1/012001

[11] Kasim, Abdul Rahman Mohd, Nur Syamilah Arifin, Noor Amalina Nisa Ariffin, Mohd Zuki Salleh, and Muhammad Imran Anwar. "Mathematical model of simultaneous flow between Casson fluid and dust particle over a vertical stretching sheet." International Journal of Integrated Engineering 12, no. 3 (2020): 253-260. 
[12] Gireesha, B. J., B. Mahanthesh, Rama Subba Reddy Gorla, and K. L. Krupalakshmi. "Mixed convection two-phase flow of Maxwell fluid under the influence of non-linear thermal radiation, non-uniform heat source/sink and fluidparticle suspension." Ain Shams Engineering Journal 9, no. $4 \quad$ (2018): $735-746$. https://doi.org/10.1016/i.asej.2016.04.020

[13] Santhosh, H. B., and C. S. K. Raju. "Unsteady Carreau-Casson fluids over a radiated shrinking sheet in a suspension of dust and graphene nanoparticles with non-Fourier heat flux." Nonlinear Engineering 8, no. 1 (2019): 419-428. https://doi.org/10.1515/nleng-2017-0158

[14] Kasim, Abdul Rahman Mohd, Nur Syamilah Arifin, Syazwani Mohd Zokri, and Mohd Zuki Salleh. "Fluid-particle interaction with buoyancy forces on Jeffrey fluid with Newtonian heating." CFD Letters 11, no. 1 (2019): 1-16.

[15] Kasim, Abdul Rahman Mohd, Nur Syamilah Arifin, Syazwani Mohd Zokri, and Mohd Zuki Salleh. "The investigation of a fluid-solid interaction mathematical model under combined convective jeffrey flow and radiation effect embedded newtonian heating as the thermal boundary condition over a vertical stretching sheet." In Defect and Diffusion Forum, vol. 399, pp. 65-75. Trans Tech Publications Ltd, 2020. https://doi.org/10.4028/www.scientific.net/DDF.399.65

[16] Dinesh, P. A., A. S. Vasudevamurthy, and M. Uma. "Effects of Forchheimer, MHD and Radiation Absorption for Chemically Reacting Unsteady Dusty Viscoelastic Fluid Couette Flow in an Irregular Channel." In Advances in Fluid Dynamics, pp. 999-1012. Springer, Singapore, 2021. https://doi.org/10.1007/978-981-15-4308-1 77

[17] Bilal, Muhammad, Salaha Khan, Farhad Ali, Muhammad Arif, Ilyas Khan, and Kottakkaran Sooppy Nisar. "Couette flow of viscoelastic dusty fluid in a rotating frame along with the heat transfer." Scientific reports 11, no. 1 (2021): 1-16. https://doi.org/10.1038/s41598-020-79795-w

[18] Parvin, Shahanaz, Siti Suzilliana Putri Mohamed Isa, Norihan Md Arifin, and Fadzilah Md Ali. "The Magnetohydrodynamics Casson Fluid Flow, Heat and Mass Transfer Due to the Presence of Assisting Flow and Buoyancy Ratio Parameters." (2021). https://doi.org/10.37934/cfdl.12.8.6475

[19] Ghiasi, Emran Khoshrouye, and Reza Saleh. "Analytical and numerical solutions to the 2D Sakiadis flow of Casson fluid with cross diffusion, inclined magnetic force, viscous dissipation and thermal radiation based on Buongiorno's mathematical model." CFD Letters 11, no. 1 (2019): 40-54.

[20] Yashkun, Ubaidullah, Fatinnabila Kamal, Khairy Zaimi, Nor Ashikin Abu Bakar, and Norshaza Atika Saidin. "Stability Analysis on Stagnation-Point Flow and Heat Transfer towards a Permeable Stretching/Shrinking Sheet with Heat Source in a Casson Fluid." CFD Letters 12, no. 6 (2020): 1-15. https://doi.org/10.37934/cfdl.12.6.115

[21] Khan, Ansab Azam, Khairy Zaimi, Suliadi Firdaus Sufahani, and Mohammad Ferdows. "MHD Flow and Heat Transfer of Double Stratified Micropolar Fluid over a Vertical Permeable Shrinking/Stretching Sheet with Chemical Reaction and Heat Source." Journal of Advanced Research in Applied Sciences and Engineering Technology 21, no. 1 (2020): 1-14. https://doi.org/10.37934/araset.21.1.114

[22] Yasin, Siti Hanani Mat, Muhammad Khairul Anuar Mohamed, Zulkhibri Ismail, Basuki Widodo, and Mohd Zuki Salleh. "Numerical solution on MHD stagnation point flow in ferrofluid with Newtonian heating and thermal radiation effect." Journal of Advanced Research in Fluid Mechanics and Thermal Sciences 57, no. 1 (2019): 12-22.

[23] Mohd Kasim, Abdul Rahman, Nur Syamilah Arifin, Syazwani Mohd Zokri, Mohd Zuki Salleh, Nurul Farahain Mohammad, Dennis Ling Chuan Ching, Sharidan Shafie, and Noor Amalina Nisa Ariffin. "Convective transport of fluid-solid interaction: A study between non-Newtonian Casson model with dust particles." Crystals 10, no. 9 (2020): 814. https://doi.org/10.3390/cryst10090814

[24] Zokri, Syazwani Mohd, Nur Syamilah Arifin, Abdul Rahman Mohd Kasim, and Mohd Zuki Salleh. "Flow of Jeffrey Fluid over a Horizontal Circular Cylinder with Suspended Nanoparticles and Viscous Dissipation Effect: Buongiorno Model." CFD Letters 12, no. 11 (2020): 1-13. https://doi.org/10.37934/cfdl.12.11.113

[25] Zokri, Syazwani Mohd, Nur Syamilah Arifin, Abdul Rahman Mohd Kasim, and Mohd Zuki Salleh. "Free Convection Boundary Layer Flow of Jeffrey Nanofluid on a Horizontal Circular Cylinder with Viscous Dissipation Effect." Journal of Advanced Research in Micro and Nano Engineering 1, no. 1 (2020): 1-14.

[26] Kasim, A., and S. Shafie. "Mixed Convection Boundary Layer of a Viscoelastic Fluid past a Circular Cylinder with Constant Heat Flux." In Proceedings of the 1st Regional Conference on Applied and Engineering Mathematics, vol. 1, no. 20, pp. 124-129. 2010.

[27] Zokri, Syazwani Mohd, Nur Syamilah Arifin, Muhammad Khairul Anuar Mohamed, Abdul Rahman Mohd Kasim, Nurul Farahain Mohammad, and Mohd Zuki Salleh. "Mathematical model of mixed convection boundary layer flow over a horizontal circular cylinder filled in a Jeffrey fluid with viscous dissipation effect." Sains Malaysiana 47, no. 7 (2018): 1607-1615. https://doi.org/10.17576/jsm-2018-4707-32

[28] Muhammad, Nura Muaz, Nor Azwadi Che Sidik, Aminuddin Saat, Yusuf Alhassan, and Yutaka Asako. "A Numerical Investigation on the Combined Effect of Aluminum-Nitride/Water Nanofluid with Different Mini-Scale Geometries for Passive Hydrothermal Augmentation." Journal of Advanced Research in Numerical Heat Transfer 1, no. 1 (2020): 1-12. 
[29] Shateyi, S., and S. S. Motsa. "Variable viscosity on magnetohydrodynamic fluid flow and heat transfer over an unsteady stretching surface with Hall effect." Boundary Value Problems 2010 (2010): 1-20. https://doi.org/10.1155/2010/257568

[30] Tshehla, M. "The flow of a variable viscosity fluid down an inclined plane with a free surface." Mathematical problems in Engineering 2013, (2013): 1-8. https://doi.org/10.1155/2013/754782

[31] Megahed, Ahmed M. "Williamson fluid flow due to a nonlinearly stretching sheet with viscous dissipation and thermal radiation." Journal of the Egyptian Mathematical Society 27, no. 1 (2019): 1-10. https://doi.org/10.1186/s42787-019-0016-y

[32] Khan, Mair, M. Y. Malik, T. Salahuddin, and Arif Hussian. "Heat and mass transfer of Williamson nanofluid flow yield by an inclined Lorentz force over a nonlinear stretching sheet." Results in Physics 8 (2018): 862-868. https://doi.org/10.1016/i.rinp.2018.01.005

[33] Dada, Moses Sunday, and Cletus Onwubuoya. "Variable viscosity and thermal conductivity effects on Williamson fluid flow over a slendering stretching sheet." World Journal of Engineering (2020). https://doi.org/10.1108/WJE$\underline{08-2019-0222}$

[34] Aljabali, Ahlam, Abdul Rahman Mohd Kasim, Nur Syamilah Arifin, Sharena Mohamad Isa, and Noor Amalina Nisa Ariffin. "Analysis of Convective Transport of Temperature-Dependent Viscosity for Non-Newtonian Erying Powell Fluid: A Numerical Approach." CMC-COMPUTERS MATERIALS \& CONTINUA 66, no. 1 (2021): 675-689. https://doi.org/10.32604/cmc.2020.012334

[35] Aljabali, Ahlam, Abdul Rahman Mohd Kasim, Nur Syamilah Arifin, and Sharena Mohamad Isa. "Mixed Convection of Non-Newtonian Erying Powell Fluid with Temperature-Dependent Viscosity over a Vertically Stretched Surface." CMC-COMPUTERS MATERIALS \& CONTINUA 66, no. 1 (2021): $421-435$. https://doi.org/10.32604/cmc.2020.012322

[36] Manjunatha, S., and B. J. Gireesha. "Effects of variable viscosity and thermal conductivity on MHD flow and heat transfer of a dusty fluid." Ain Shams Engineering Journal 7, no. 1 (2016): 505-515. https://doi.org/10.1016/i.asej.2015.01.006

[37] Bibi, Madiha, A. Zeeshan, M. Y. Malik, and K. U. Rehman. "Numerical investigation of the unsteady solid-particle flow of a tangent hyperbolic fluid with variable thermal conductivity and convective boundary." The European Physical Journal Plus 134, no. 6 (2019): 1-14. https://doi.org/10.1140/epip/i2019-12651-9

[38] Konch, Jadav. "Soret and Dufuor Effects on Unsteady Hydromagnetic Dusty Fluid Flow past an Exponentially Accelerated Plate with Variable Viscosity and Thermal Conductivity." Frontiers in Heat and Mass Transfer (FHMT) 10, no.29 (2018): 1-18. https://doi.org/10.5098/hmt.10.29

[39] Ali, Liaqat, Xiaomin Liu, and Bagh Ali. "Finite element analysis of variable viscosity impact on mhd flow and heat transfer of nanofluid using the cattaneo-christov model." Coatings 10, no. $4 \quad$ (2020): 395. https://doi.org/10.3390/coatings10040395

[40] Crane, Lawrence J. "Flow past a stretching plate." Zeitschrift für angewandte Mathematik und Physik ZAMP 21, no. 4 (1970): 645-647. https://doi.org/10.1007/BF01587695

[41] Salleh, Mohd Zuki, Roslinda Nazar, and I. Pop. "Boundary layer flow and heat transfer over a stretching sheet with Newtonian heating." Journal of the Taiwan Institute of Chemical Engineers 41, no. 6 (2010): 651-655. https://doi.org/10.1016/j.jtice.2010.01.013 